\title{
Effects of local anesthesia and flunixin meglumine on the acute cortisol response, behavior, and performance of young dairy calves undergoing surgical castration
}

\author{
H. B. Webster, ${ }^{* 1}$ D. Morin, ${ }^{*}$ V. Jarrell, $†$ C. Shipley, ${ }^{*}$ L. Brown, ${ }^{*}$ A. Green, $\ddagger$ R. Wallace, ${ }^{\star} \S$ and P. D. Constable\# \\ ${ }^{*}$ College of Veterinary Medicine, \\ †Department of Animal Sciences, and \\ ‡Department of Agricultural and Biomedical Engineering, University of Illinois, Urbana 61802 \\ §Pfizer Animal Health Veterinary Operations, Champaign, IL 61820 \\ \#College of Veterinary Medicine, Purdue University, West Lafayette, IN 47907
}

\section{ABSTRACT}

This study assessed the effects of flunixin meglumine (FM) and a local anesthetic block (LA) on postcastration performance, plasma cortisol concentration, and behavior in dairy calves. Thirty 2- to 3-mo-old Holstein-Friesian bull calves were allocated to 5 treatments: castration with LA (2\% lidocaine injected into the testes and subcutaneously), castration with FM $(1.1 \mathrm{mg} / \mathrm{kg}$, i.v. $)$, castration with $\mathrm{LA}+\mathrm{FM}$, castration without drugs (CC), and sham castration (SC). Castration was performed using a Newberry knife and Henderson castrating tool. Feed intake and body weight gain were recorded for $10 \mathrm{~d}$ postcastration. Plasma cortisol concentration and behavior frequency and duration were monitored for $8 \mathrm{~h}$ postcastration. Variables with repeated measures were analyzed using PROC MIXED (SAS Institute Inc., Cary, NC); oneway ANOVA was used for nonrepeated measures. No differences in feed intake or body weight gain were detected among groups. Calves in the CC, LA, and FM groups had transient $(<60,<60$, and $<45 \mathrm{~min}$, respectively) increases in plasma cortisol concentration after castration, with a second increase at $120 \mathrm{~min}$ in the LA group, whereas cortisol concentration remained at baseline in the LA+FM and SC groups. Mean cortisol concentrations were lower for calves in the $\mathrm{LA}+\mathrm{FM}$ and SC groups than in the CC group. The area under the plasma cortisol concentration curve during the first $3 \mathrm{~h}$ postcastration was greater in CC- and LA-treated calves than in SC controls. Castration without drugs was associated with higher frequencies of crouching and statue standing and less oral activity compared with SC controls. Administering LA alone before castration was associated with higher frequencies of head turning, statue standing, and postural changes, and less feeding

Received October 5, 2012.

Accepted June 19, 2013.

${ }^{1}$ Corresponding author: hbwebster@gmail.com behavior compared with SC controls. More leg lifting to groom was seen in LA+FM-treated calves than in SC controls. Calves administered FM alone before castration exhibited less crouching than CC calves, fewer postural shifts, and more feeding behavior than LA-treated calves. In summary, FM alone tended to shorten the duration of cortisol response and reduce crouching after surgical castration. Combining $\mathrm{LA}+\mathrm{FM}$ eliminated the cortisol response to castration but was associated with more leg lifting behavior. Treatment with LA alone did not mitigate the cortisol response and was associated with several behavioral differences compared with SC, FM-treated, or FM+LA-treated calves. Results suggest that LA alone did not effectively control discomfort in young dairy calves castrated using the Henderson castration tool.

Key words: dairy calf, surgical castration, anesthesia, analgesia

\section{INTRODUCTION}

Castration of bull calves is a painful yet routine husbandry procedure with well-described benefits (Faulkner et al., 1992; Arave and Albright, 1997; Fisher et al., 2001; Earley and Crowe, 2002; Stafford and Mellor, 2005a; Stafford, 2007; Currah et al., 2009; AVMA, 2012). Pain management for castration is legislated in many countries; for instance, in the United Kingdom, castration of calves $\geq 2$ mo of age requires an anesthetic and must be performed by a veterinarian. Castration of calves is a focus of animal welfare discussions in the United States, and the American Veterinary Medical Association (AVMA) recommends castrating calves at the earliest age practicable using procedures and practices that reduce or eliminate pain and discomfort, including the use of approved or AMDUCA (Animal Medicinal Drug Use Clarification Act)-permissible clinically effective medications whenever possible (AVMA, 2008). A 2009 report from the Canadian National Farm Animal Care Council (NFACC) concluded that 
all methods of castration cause pain but that this can be reduced through the appropriate use of local anesthetics and longer-lasting analgesics (NFACC, 2009). Currently, the United States and Canada do not have legislation related to the age of calf, method of castration, or use of anesthetic or analgesic agents when castrating cattle.

Castration is commonly carried out at less than 3 mo of age in calves on US beef operations (USDA-APHIS, 2008). Although similar information regarding age of castration in dairy calves is not available in the United States, it is convenient for dairy producers to castrate bull calves that are to be raised for beef when they wean the calves at 2 to 3 mo of age. Most published studies investigating pain and stress responses accompanying castration and the effects of anesthetic or analgesic agents involve calves older than 3 mo of age (Stafford and Mellor, 2005a; Currah et al., 2009; Stewart et al., 2010).

The most common methods used to castrate beef calves in the United States involve surgical incision of the scrotum and removal of the testes (USDA-APHIS, 2008; Coetzee et al., 2010). Compared with other methods, surgical castration has been associated with more marked acute pain and stress responses (Robertson et al., 1994; Fisher et al., 2001; Earley and Crowe, 2002; Stafford et al., 2002). Approaches to alleviate castration-associated pain and stress include local or epidural anesthesia (Earley and Crowe, 2002; Currah et al., 2009), sedation (Faulkner et al., 1992; Ting et al., 2003a), and administration of nonsteroidal antiinflammatory drugs (NSAID; Coetzee et al., 2007; Stilwell et al., 2008; Currah et al., 2009). Unfortunately, no analgesic drugs are approved for pain relief in calves in the United States (AVMA, 2012). However, according to a recent US survey of bovine veterinarians, 1 in 5 respondents reported using an analgesic or anesthetic agent at the time of castration (Coetzee et al., 2010). Such extra-label drug use should be guided by scientific evidence of efficacy in the target population.

Lidocaine $\mathrm{HCl}$ is the local anesthetic agent (LA) typically used for pain relief in cattle in the United States. Local administration of lidocaine into the testes or spermatic cords or subcutaneously has reduced short-term responses indicative of pain or stress in some (Thüer et al., 2007) but not all (Fisher et al., 1996; Stafford et al., 2002; Rust et al., 2007) studies. Pain responses may increase once lidocaine concentration declines, as seen after dehorning procedures (Stafford and Mellor 2005b). The only Food and Drug Administration-approved NSAID for use in cattle in the United States is flunixin meglumine (FM), which is labeled for intravenous administration in respiratory disease and endotoxemia as an antipyretic and antiinflammatory agent (Smith et al., 2008). Most studies of the analgesic effects of NSAID in young calves involve agents other than FM (Earley and Crowe, 2002; Stafford et al., 2002; Ting et al., 2003a; Coetzee et al., 2007). Studies using FM combined with LA can be found for the Burdizzo clamping technique (Stilwell et al., 2008), rubber ring technique (Marti et al., 2010), and surgical technique (Currah et al., 2009), with mixed results.

Objectives of the study reported here were to quantify acute behavioral, physiologic, and performance effects of surgical castration in dairy calves at 2 to $3 \mathrm{mo}$ of age when (1) no anesthetic or analgesic agents were administered, (2) a local anesthetic agent (LA; lidocaine $\mathrm{HCl}$ ) was injected into the testes and as a subcutaneous ring block around the spermatic cords, (3) a single dose of FM was administered i.v., or (4) FM and LA were administered in combination. Based on previous published findings for calves being castrated (Stafford and Mellor, 2005a) and dehorned (Stafford and Mellor, 2005b), we hypothesized that calves castrated at 2 to 3 mo of age would exhibit a transient decrease in feed intake, a pronounced but transient increase in plasma cortisol concentration, and behaviors indicative of pain or stress if no anesthetic or analgesic agents were administered. We expected LA to reduce painand stress-associated responses during the first 1 to 2 $\mathrm{h}$ postoperatively, and FM to reduce responses mainly during the inflammatory phase of the pain response, from $2 \mathrm{~h}$ postcastration onward. We hypothesized that administering both FM and LA would result in responses similar to those of control animals that were handled but not castrated.

\section{MATERIALS AND METHODS}

The Institutional Animal Care and Use Committee (IACUC) of the University of Illinois at UrbanaChampaign approved all procedures involving animals in this study (protocol \# 09115).

\section{Animals and Husbandry}

Thirty weaned Holstein-Friesian bull calves from the University of Illinois Dairy Research Unit were used. Calves were 2 to 3 mo of age (range 59 to $91 \mathrm{~d}$ ) and weighed 69 to $94 \mathrm{~kg}$ at enrollment. Calves had been previously habituated to intensive handling and individual housing in another research facility. They were deemed healthy on the basis of history and physical examination. Calves were housed in a naturally ventilated barn in 5 individual sawdust-bedded, wire-panel pens that allowed nose-to-nose contact between adjacent pens. Bedding was replaced twice daily. The diet consisted of a balanced, mixed ration containing haylage and com- 
mercial calf pellets. Calves had ad libitum access to feed and water. Fresh feed was provided and refused feed removed twice daily.

\section{Study Design and Treatments}

The study was conducted in 6 replicates between September and December 2009. Mean ambient temperature ranged from 7 to $22^{\circ} \mathrm{C}$ for the 6 study days (http://www.isws.illinois.edu/atmos/statecli/ cuweather/). Calves were given $4 \mathrm{~d}$ to acclimate to their new environment $(\mathrm{d}-4$ to -1$)$. On $\mathrm{d}-1$, a 16 -gauge $\times$ 2" indwelling catheter (Angiocath, BD Medical, Sandy, UT) was aseptically placed into the left jugular vein and anchored to the skin with sutures. Treatments were administered on $\mathrm{d} 0$ and calves monitored for the following $10 \mathrm{~d}$.

Within a replicate, calves were randomly assigned, by order of arrival, to 5 treatments: castration control (CC), LA only, FM only, combination of LA and FM $(\mathbf{L A}+\mathbf{F M})$, and sham-castration control (SC). On d 0 , the calf in pen 1 was castrated (or sham-castrated) first, followed sequentially by the calves in pens $2,3,4$, and 5. To avoid confounding due to pen location (end pens vs. middle pens) and position in castration sequence (first, second, third, fourth, or fifth), assignment of calves to pens was stratified by treatment group. Calves in the sixth replicate were randomly assigned to pens. Computer-generated random numbers (Excel 2007, Microsoft Corp., Redmond, WA) were used for randomization.

Calves were haltered and walked to a chute on the morning of $\mathrm{d} 0$. They were restrained in a head gate with their halters loosely tied to the side of the chute. No squeeze, tail press, or other restraint method was applied during treatment. Calves in the LA+FM group were administered FM (Flunixiject, Butler Animal Health Supply, Dublin, OH) at a dose of $1.1 \mathrm{mg} / \mathrm{kg}$ (approximately 1.5 to $2 \mathrm{~mL}$ ) i.v. via the jugular catheter. Volumes were calculated from individual calf weights obtained on the day of treatment. The calves were then administered $20 \mathrm{~mL}$ of $2 \%$ lidocaine $\mathrm{HCl}$ (Hospira Inc., Lake Forest, IL) in a subcutaneous ring block at the neck of the scrotum, just above the testes (Stewart et al., 2010). The 1.5-inch, 18-gauge needle used to inject the lidocaine was withdrawn and reintroduced under the skin a total of 4 times during the block, to deposit the lidocaine circumferentially around, but not into, the spermatic cords. An additional $2.5 \mathrm{~mL}$ of lidocaine $\mathrm{HCl}$ was injected directly into each testicle (Stewart et al., 2010). Calves in the LA group were administered lidocaine but given a placebo $(2 \mathrm{~mL}$ of sterile $0.9 \% \mathrm{NaCl}$ solution i.v.) rather than FM. Calves in the FM group received FM i.v., and the scrotal skin and testes were handled to simulate administration of lidocaine without needle insertion. Calves in the CC and SC groups were treated similarly to those in the FM group but received the $0.9 \% \mathrm{NaCl}$ placebo (2 $\mathrm{mL}$ i.v.). Calves were held in the chute for 20 min after administering treatments before castration or sham-castration, to allow distribution of FM and time for the LA to take effect. An IACUCapproved rescue protocol, based on appetite, attitude, and criteria pertaining to the surgical site, was in place to ensure that calves exhibiting excessive postsurgical inflammation or signs consistent with unalleviated pain or distress were removed from the study and treated as deemed appropriate by the field veterinarian.

Immediately before castration or sham castration, the scrotal skin was washed with dilute chlorhexidine solution and water using paper towels. An assistant loosely held the tail to the side. The surgeon grasped the bottom of the scrotum and pushed the testes proximally. One incision in the vertical plane was made in a downward direction through the scrotal skin with a Newberry knife (Syrvet Inc., Waukee, IA), with the insertion site approximately at the right lateral midpoint of the scrotum, exposing both testes within their tunics. Each testis and associated spermatic cord was isolated by manually separating it from the surrounding fascia. A Henderson castrating tool (Stone Manufacturing \& Supply Company Inc., Kansas City, MO), connected to an 18-V cordless drill (DeWalt Industrial Tool Co., Baltimore, MD) with a $3 / 8$ " chuck was clamped to the spermatic cord immediately proximal to the testis and the drill powered to rotate and sever the cord as described by Coetzee et al. (2007). Hemostasis was not required and the wound was left open to drain. Calves in the SC group were sham-castrated by washing and handling the scrotum as if to castrate, moving the back side of the Newberry knife against the skin and running the drill for a few seconds. After castration or shamcastration, calves were walked back to their pens, where fresh feed was available.

A single operator (H.B.W.) administered the lidocaine and castrated the calves to ensure consistency of technique across all groups. Therefore, the 5 calves within a replicate were treated sequentially over the course of approximately $2 \mathrm{~h}$ on $\mathrm{d} 0$. This occurred between 0830 and $1130 \mathrm{~h}$ to minimize the effect of diurnal variation on plasma cortisol concentration (Thun et al., 1981).

\section{Feed Intake and BW Gain}

The weights of feed offered and feed refused were used to calculate feed intake. Feed intake in the morning was added to feed intake in the afternoon to determine daily feed intake for each calf. Feed intake on d 
-4 and 10 were excluded from the analysis because the trial encompassed only one feeding time on those days. Calves were weighed on an electronic scale at enrollment on $\mathrm{d}-4$ and again on $\mathrm{d}-2,0$, and 10 . Baseline BW was determined by averaging the 3 precastration weights for each calf, and BW change was calculated by subtracting the baseline weight from weight on $\mathrm{d} 10$.

\section{Plasma Cortisol Concentration}

Blood (5 to $6 \mathrm{~mL}$ per sample) was collected from the jugular catheter at approximately $-20,0,15,30$, $45,60,90,120,150,180,210,240,300,360,420$, and $480 \mathrm{~min}$ relative to the time of castration $(0 \mathrm{~min})$. The -20 and 0 min samplings were performed while the calf was restrained in the chute. The -20 min sample was taken just after the calf was secured in the chute and immediately before drug treatments were administered. The 0 min sample was taken immediately after castration or sham-castration. The remaining samples were obtained with minimal handling while the calf was in its assigned pen. The catheter was flushed with heparinized saline solution (heparin sodium, $10 \mathrm{IU} / \mathrm{mL}$ ) before and after each blood collection. The catheter was removed after obtaining the final sample. At each sampling time, the first $6 \mathrm{~mL}$ of blood was withdrawn and not included in the test sample. The test sample was then drawn, transferred to a $6-\mathrm{mL}$ sterile tube, and immediately centrifuged at $1,500 \times g$ for 15 min at room temperature. Duplicate aliquots of the harvested plasma were placed on ice for the remainder of the 8-h sampling period. Aliquots were then stored at $-20^{\circ} \mathrm{C}$ until analysis. Plasma cortisol concentration $(\mathrm{ng} / \mathrm{mL})$ was measured using a commercially available ELISA kit (Cortisol ELISA RE52061, IBL International Corp., Toronto, ON, Canada).The minimum detectable cortisol concentration of the assay was $2.5 \mathrm{ng} / \mathrm{mL}$. To determine coefficients of variation $(\mathbf{C V})$ of the assay, we used 2 plasma samples with different cortisol concentrations (28.6 and $10.3 \mathrm{ng} / \mathrm{mL}$ ). The intraassay CV was determined by pipetting each sample into 5 wells in duplicate on the same plate. Variation within the assay was 4.0 and $7.3 \%$ for the high and low concentration samples, respectively. The interassay CV was determined by plating the 2 samples in duplication 4 different plates run in series; this yielded CV of 17.1 and $9.8 \%$, respectively.

\section{Behavior}

Two infrared light-emitting diode video cameras (Defender Security $3.6 \mathrm{~mm}$ Color Day/Night Bullet Camera \#82-11365, MCM Electronics, Centerville, $\mathrm{OH})$ were mounted to capture a clear view of all 5 calves simultaneously. The cameras were secured in front of and above the pens to observe the entire depth of each pen. Physical activity was recorded continuously from the time the calves returned to their pens on d 0 until $8 \mathrm{~h}$ after castration or sham castration. The data were stored on a DVR capture card (Geovision Combo Card GV1240, Geovision Inc., Irvine, CA) and analyzed 6 mo after trial completion. Video playback was performed using the same DVR software. A single observer (H.B.W.) viewed the continuous recordings for the entire 8-h postcastration (PC) period for each calf. Behaviors were quantified using ethological variables and definitions (Table 1) modified from those used by Molony et al. (1995) and Thüer et al. (2007). Discrete behaviors, such as kicking and licking, were quantified by frequency of occurrence (frequency events), whereas continuous behaviors, such as standing and lying, were quantified by duration (duration events).

\section{Statistical Analysis}

Data were $\log _{10}$-transformed or ranked as needed to achieve a normal distribution. Results are reported as least squares means and standard errors or as geometric means and ranges. Analyses were conducted using SAS (version 9.3, SAS Institute Inc., Cary, NC). Significance was declared at $P<0.05$. Results with $P$-values between 0.05 and 0.10 were considered to approach significance and reported as tendencies. Variables with repeated measures (feed intake, BW, plasma cortisol concentration) were analyzed using the PROC MIXED procedure and an autoregressive (1) structure, with calf as the experimental unit. Fixed effects were treatment, time, and the interaction of treatment and time. When an effect was significant, Bonferroni-adjusted $P$-values were used to assess the significance of planned comparisons among groups or time points.

The primary variable of interest was whether treatment affected the change in plasma cortisol concentration over time. Behavior, feed intake, and BW were evaluated to identify behaviors of greatest interest and to provide information to assist calculation of statistical power for future studies. Changes in plasma cortisol concentration over time within a treatment group were determined by comparing values to the $-20 \mathrm{~min}$ concentration. Variables with single measures [BW gain, maximum plasma cortisol concentration (Cmax), time to maximum plasma cortisol concentration (Tmax), integrated cortisol response (area under the cortisol curve, AUC), and behavior durations] were analyzed using one-way ANOVA. The Tmax and Cmax values were observed directly from the data. The AUC was determined using the value at $-20 \mathrm{~min}$ as the baseline and calculating the area of response above that base- 
Table 1. Description of behaviors observed in 2- to 3-mo-old calves immediately following surgical or sham castration

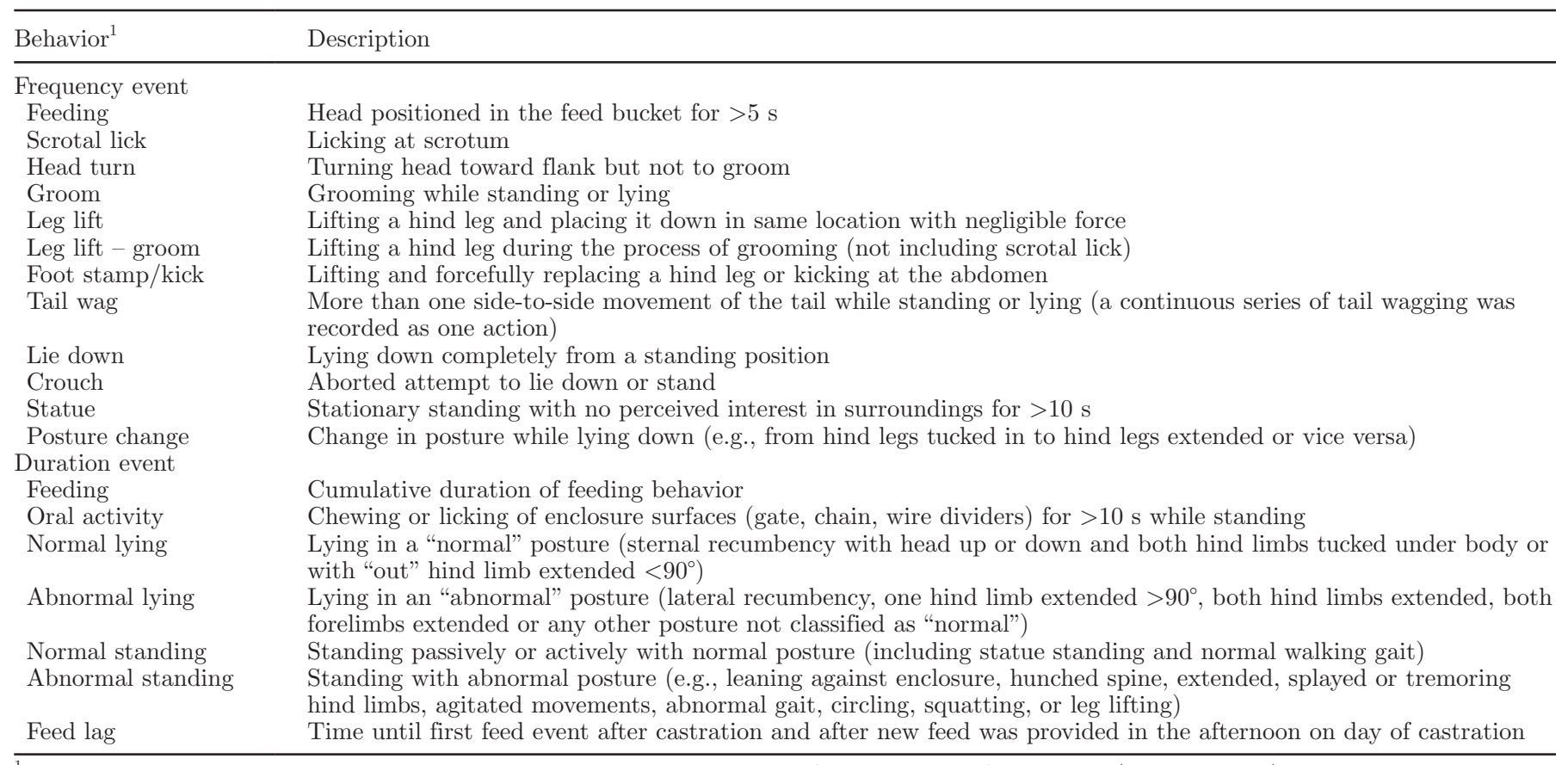

${ }^{1}$ Behaviors were observed using continuous video recording and analyzed from the time of castration (time $=0 \mathrm{~min}$ ) through $3 \mathrm{~h}$ or $8 \mathrm{~h}$ postcastration.

line using the trapezoidal method. An additional fixed effect of day (6 levels) was examined in the ANOVA procedure for indices related to cortisol to determine whether study day was a potential confounder. Frequency of behaviors was analyzed using the negative binomial model (PROC GENMOD). This method of analysis was selected because frequency data were count outcomes and a small number of studied variables contained excess zeros and overdispersion (White and Bennetts, 1996; Coxe et al., 2009). The dependent variable was the number of behaviors observed, and the independent variable was treatment group. Whenever an effect of treatment (or study day for the 6 indices related to cortisol) was significant, Bonferroni-adjusted $P$-values were used to assess the significance of differences between treatments and days. Separate analyses were conducted for the full data set (through $8 \mathrm{~h}$ after castration or sham castration) and for data collected through the first $3 \mathrm{~h}$ after castration or sham castration; these time points were selected based on the results of previous studies that indicated changes in cortisol concentration and behavior were most pronounced during the first $3 \mathrm{~h}$ after castration (Fell et al., 1986; Robertson et al., 1994; Stafford et al., 2002).

\section{RESULTS}

Calves were treated and castrated without difficulty, and no calves experienced postsurgical hemorrhage, infection, or systemic disease. None of the calves met the criteria for the IACUC-approved rescue treatment or required removal from the study.

\section{Feed Intake and Weight Gain}

Feed intake increased over the course of the study $(P<0.001$; Table 2 , Figure 1$)$ but varied substantially among individual calves. Mean feed intake did not differ among treatment groups $(P=0.98)$ and no treatment $\times$ time interaction was detected $(P=0.41)$. Body weight also increased over time $(P<0.001$; Table 2$)$. Mean BW $(P=0.97)$ or BW change $(P=0.66$ : Table $2)$ did not differ among treatment groups, and no treatment $\times$ time interactions $(P=0.69)$ were found.

\section{Plasma Cortisol Concentration}

For results pertaining to plasma cortisol concentration, the Bonferroni-adjusted $P$-value required to declare significant differences between treatment groups was $<0.005$, and the Bonferroni-adjusted $P$-value required to declare a significant difference from baseline concentration within a treatment group was $<0.0033$ (8-h analysis) or $<0.0056$ (3-h analysis).

Mean Plasma Cortisol Concentration. Mean plasma cortisol concentrations for the 3 -h and 8-h PC periods are shown in Table 3. Calves given LA+FM before castration and calves in the SC control group 
Table 2. Least squares mean BW (kg), change in BW $(\mathrm{kg})$, and daily feed intake ( $\mathrm{kg}$, wet weight) for 2- to 3 -mo-old calves $(\mathrm{n}=6$ /group) castrated surgically without anesthesia or analgesia (CC) or administered a local anesthetic agent (LA) with and without an i.v. injection of flunixin meglumine (FM)

\begin{tabular}{lccccc}
\hline & \multicolumn{2}{c}{ BW $(\mathrm{kg})$} & & \multicolumn{2}{c}{ Feed intake $(\mathrm{kg})$} \\
\cline { 2 - 3 } \cline { 5 - 6 } Treatment & $\begin{array}{c}\text { On d } 0 \\
(\mathrm{SE}=3.3)\end{array}$ & $\begin{array}{c}\text { BW change } \\
(\mathrm{SE}=4.9)\end{array}$ & & $\begin{array}{c}\mathrm{d} 0 \\
(\mathrm{SE}=0.4)\end{array}$ & $\begin{array}{c}\mathrm{d} 9 \\
(\mathrm{SE}=0.4)\end{array}$ \\
\hline CC & 78.9 & 7.8 & 8.9 & 2.3 & 3.8 \\
LA & 79.5 & 8.1 & & 2.5 & 3.8 \\
FM & 79.7 & 6.6 & & 3.7 & 3.3 \\
LA+FM & 80.1 & 10.8 & & 2.5 & 3.6 \\
SC $^{2}$ & 76.6 & & & & 3.9 \\
\hline
\end{tabular}

${ }^{1}$ Weight change calculated by subtracting baseline weight from weight on d 10. Day $0=$ day of castration.

${ }^{2} \mathrm{SC}=$ sham-castrated controls $(\mathrm{n}=6)$.

had lower mean plasma cortisol concentrations than did calves castrated without drugs $(3 \mathrm{~h}: P \leq 0.004$; 8 h: $P \leq 0.002)$. No other significant differences were detected among treatment groups. However, calves in the LA group tended to have higher mean cortisol concentrations than did the SC controls $(P<0.008$ for both periods).

Plasma Cortisol Concentration over Time. Figure 2 shows mean plasma cortisol concentrations for each treatment group at each time point. Significant time and treatment $\times$ time effects were identified for both the 3- and 8-h analyses. Results of the 8-h analysis are described here. Baseline $(-20 \mathrm{~min})$ cortisol concentration did not differ among treatment groups $(P \geq 0.27)$. Calves in the CC, LA, and FM groups experienced increases in plasma cortisol concentration in response to castration $(P<0.0033)$. In contrast, plasma cortisol concentration did not increase above baseline in $\mathrm{SC}$ calves or calves given $\mathrm{LA}+\mathrm{FM}(P \geq$ $0.18)$.

Plasma cortisol concentration increased immediately in calves castrated without drugs and was higher than baseline through 60 min $\mathrm{PC}(P<0.0033)$. At $15,30,45$, and $60 \mathrm{~min} \mathrm{PC}$, plasma cortisol concentration in those calves was higher $(P \leq 0.001)$ than in calves receiving $\mathrm{LA}+\mathrm{FM}$ or in $\mathrm{SC}$ controls. At $45 \mathrm{~min} \mathrm{PC}$, plasma cortisol concentration was also higher $(P=0.003)$ than in calves receiving FM only. From 90 min PC onward, plasma cortisol concentration of calves castrated without drugs did not differ from baseline concentration $(P$

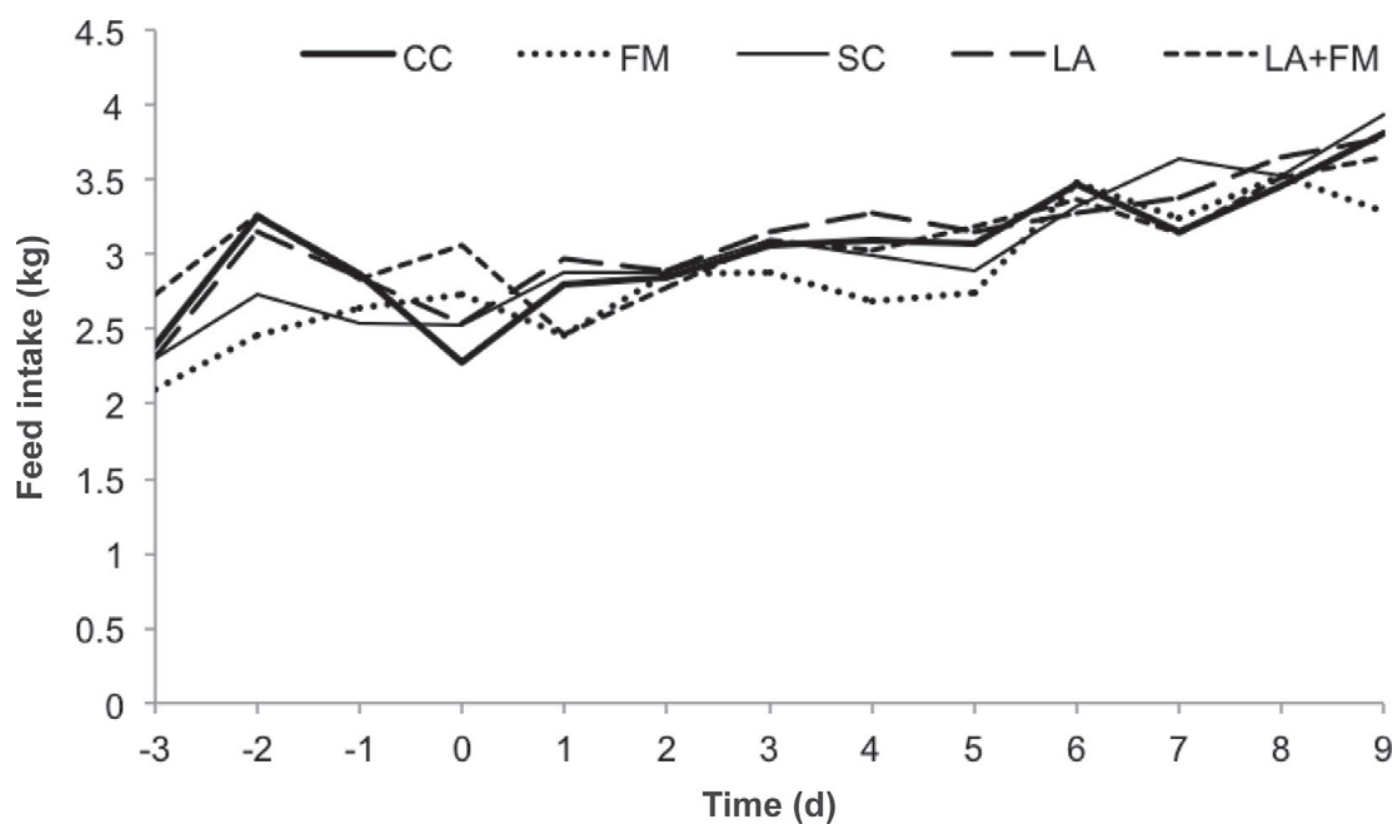

Figure 1. Least squares means daily wet feed intake $(\mathrm{SE}=0.39)$ for calves castrated surgically without anesthesia or analgesia $(\mathrm{CC})$ or administered a local anesthetic agent (LA), i.v. injection of flunixin meglumine (FM), or a combination of both treatments (LA+FM) before castration ( $\mathrm{n}=6$ /group); $\mathrm{SC}=$ sham-castrated controls $(\mathrm{n}=6)$; $\mathrm{d} 0=$ day of castration. 
Table 3. Least squares means of plasma cortisol parameters (measured through 3 and $8 \mathrm{~h} \mathrm{after}$ castration) for calves castrated surgically without anesthesia or analgesia (CC) or administered a local anesthetic agent (LA) with or without an i.v. injection of flunixin meglumine (FM) before castration $(\mathrm{n}=6 /$ group$)$

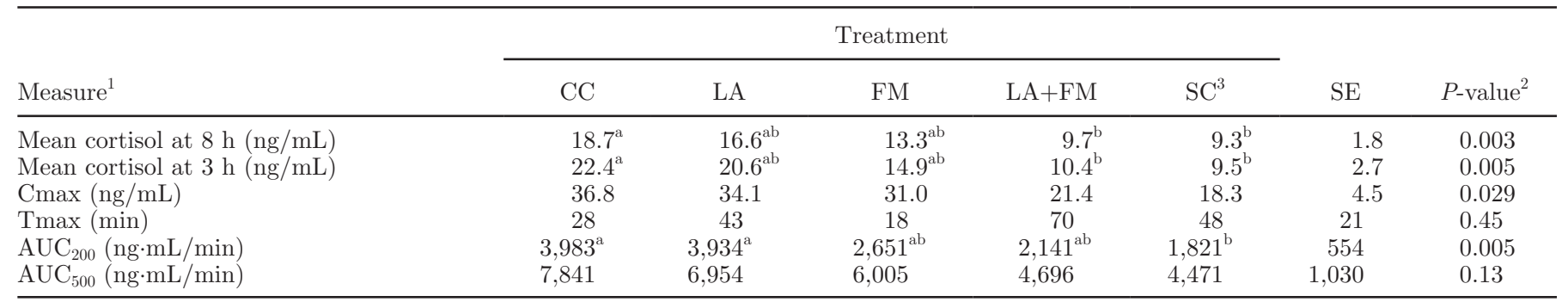

${ }^{\mathrm{a}, \mathrm{b}}$ Least squares means with different superscripts within a row are significantly different $(P<0.005$ after Bonferroni adjustment).

${ }^{1} \mathrm{Cmax}=$ maximum cortisol concentration during the 3-h period after castration; Tmax $=$ time to maximum cortisol concentration during the 3 - $\mathrm{h}$ period after castration; $\mathrm{AUC}_{200}=$ area under the cortisol concentration curve from -20 to 180 min relative to castration; $\mathrm{AUC}_{500}=$ area under the cortisol concentration curve from -20 to 480 min relative to castration.

${ }^{2} P$-value for the main effect of treatment.

${ }^{3} \mathrm{SC}$ group $=$ sham-castrated controls $(\mathrm{n}=6)$.

$\geq 0.05)$ or from those in calves of the other groups ( $P$ $\geq 0.03)$.

Plasma cortisol concentration in LA-treated calves was higher than baseline from 15 to $60 \mathrm{~min}$ PC $(P<$ $0.0033)$, followed by a second increase at $120 \mathrm{~min}(P$ $=0.001$ ) that was less intense and of shorter duration. By 150 min PC, plasma cortisol concentration had returned to baseline. At 15,30 , and $45 \min (P \leq 0.002)$
$\mathrm{PC}$, and again at $120 \mathrm{~min}(P=0.001) \mathrm{PC}$, plasma cortisol concentration was higher in LA calves than in SC controls. At 30, 45, and 60 min PC, plasma cortisol concentration was higher in LA calves than in calves given $\mathrm{LA}+\mathrm{FM}(P \leq 0.004)$. The cortisol concentration at $120 \mathrm{~min}$ in the LA calves tended to be higher than that in calves given FM $(P=0.008)$ or $\mathrm{LA}+\mathrm{FM}(P=$ 0.007).

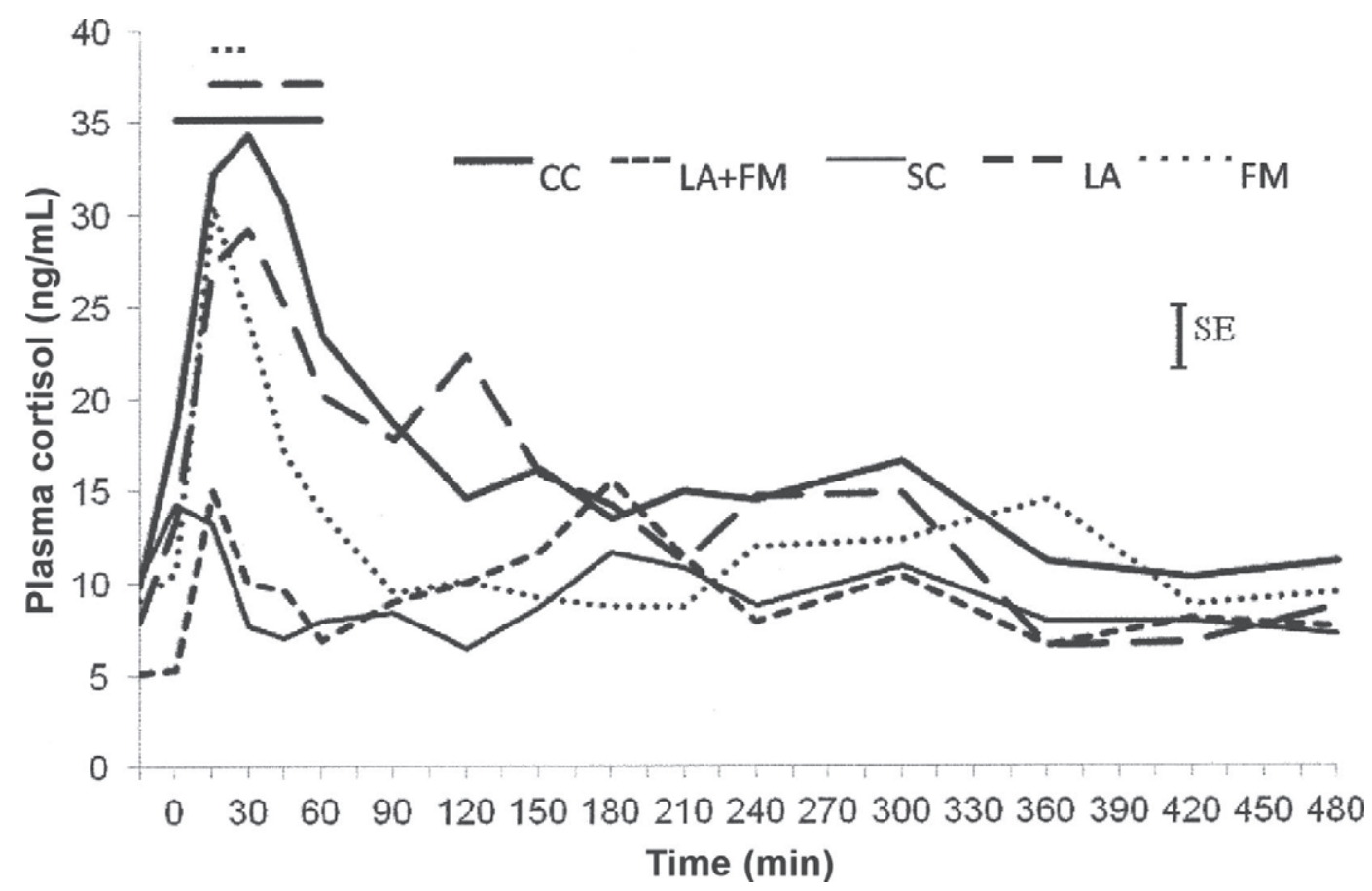

Figure 2. Least squares means plasma cortisol concentration values over time for calves castrated surgically without anesthesia or analgesia (CC) or administered a local anesthetic agent (LA), an i.v. injection of flunixin meglumine (FM) or a combination of both treatments (LA+FM) before castration $(\mathrm{n}=6$ /group). The $\mathrm{SC}$ calves were sham-castrated controls $(\mathrm{n}=6)$. Drug or placebo administration was performed 20 min before castration or sham castration $(t=-20 \mathrm{~min}$ ). Time $0=$ time of castration. Lines at the top of the graph correspond to the matching treatment group and represent the time period from 0 to 180 min where cortisol values were significantly different $(P<0.0056$ after Bonferroni adjustment) from baseline. Vertical bar represents the overall standard error (SE) for least squares means. 
Calves in the FM group had a short, sharp increase in plasma cortisol concentration, which peaked at 15 min and returned to baseline by 45 min PC. At 15 and 30 min PC, plasma cortisol concentration was higher in FM calves than in calves receiving $\mathrm{LA}+\mathrm{FM}$ and in $\mathrm{SC}$ controls $(P \leq 0.002$ and $P \leq 0.001$, respectively).

Although the 15 min PC peak seen in the LA+FM group in Figure 2 tended to be higher than baseline $(P$ $=0.007)$, the increase was not significant.

We observed no main effect of study day (6 levels) on 5 of the 6 indices related to cortisol $(P>0.05)$; however, we did observe a significant $(P=0.039)$ main effect of day for cortisol AUC from -20 to $480 \mathrm{~min}$ relative to castration $\left(\mathbf{A} \mathbf{U} \mathbf{C}_{500}\right)$. Bonferroni adjusted $P$-values for post-tests did not identify any day-to-day differences in cortisol $\mathrm{AUC}_{500}$. These findings suggest the absence of a potential confounding effect of season on plasma cortisol indices.

Cmax and Tmax. We observed great variability in maximum plasma cortisol concentration (Cmax) and time to Cmax (Tmax) among individual calves, and these parameters did not differ among treatment groups (Table 3$)$. The Cmax tended to be higher $(P=$ 0.008 ) for calves castrated without analgesia or anesthesia than for SC calves (Table 3).

Area under the Plasma Cortisol Concentration Curve. Table 3 shows that the integrated cortisol response for the period between -20 and $180 \mathrm{~min}$ PC $\left(\mathbf{A U C}_{\mathbf{2 0 0}}\right)$ was not different for FM- or LA+FM-treated calves compared with SC controls $(P=0.16$ and $P=$ 0.06, respectively). However, $\mathrm{AUC}_{200}$ for calves given LA only and calves castrated without drugs were significantly greater than $\mathrm{AUC}_{200}$ of $\mathrm{SC}$ controls $(P \leq 0.003)$. Differences in integrated cortisol responses among groups for the entire observation period $\left(\mathrm{AUC}_{500}\right)$, although similar in magnitude to differences in $\mathrm{AUC}_{200}$, were not statistically significant.

\section{Behavior}

The negative binomial model provided $P$-values for frequency comparisons of interest except for the frequency of crouching behavior in a 3-h period; the latter result was due to the lack of crouching behavior in SC calves. Calves castrated without anesthetic or analgesic agents exhibited more crouching during the 8-h PC periods $(P=0.001)$ and expressed more statue standing in the 8-h $(P=0.002)$ and 3 -h $\mathrm{PC}(P<0.005)$ periods than did SC calves (Figure 3). Calves castrated without drugs also spent less time exhibiting oral activity $(P$ $=0.002$ ) in the 8 -h PC period (Figure 3 ). We were unable to detect an effect of castration without drugs on the frequency of feeding, foot stamping, scrotal licking, grooming, tail flicking, head turning, or leg lifting, compared with SC controls (Table 4). Although castration without anesthetic or analgesic agents appeared to substantially reduce mean time spent lying in a normal position and increase mean time spent standing in abnormal positions (Table 5), we observed high variability among individual calves and differences in mean values were not significant.

Most behaviors for drug-treated calves were not significantly different from those for $\mathrm{CC}$ or $\mathrm{SC}$ controls (Tables 4 and 5; Figure 3). No significant behavioral differences were detected between LA-treated calves and calves castrated without drugs. Compared with SC controls, calves treated with LA or LA+FM exhibited more leg lifting to groom in the first $3 \mathrm{~h}$ after castration $(P<0.002$; Figure 3$)$, and more scrotal licking in the first $3 \mathrm{~h}$ after castration $(P<0.002$; Table 4$)$. Calves administered LA alone also exhibited a higher frequency of head turning $(P<0.001)$ during the first $3 \mathrm{~h} \mathrm{PC}$, and a higher frequency of statue standing $(P<0.001)$ and more posture changes from standing to recumbent $(P<0.001)$ during the 3 -h and 8 -h PC periods (Table 4; Figure 3). Calves treated with LA alone also spent less time feeding in the first $8 \mathrm{~h} \mathrm{PC}(P=0.005$; Figure 3 ) and expressed a higher frequency of tail flicking in the 3-h PC period compared with the SC controls $(P<$ 0.001; Table 4). No significant differences in behaviors were observed between calves administered FM alone and SC control calves.

With respect to comparisons among drug-treated groups, FM-treated calves exhibited fewer $(P<0.003)$ posture shifts from standing to recumbent than did LA-treated calves in the 3-h and 8-h PC periods, and more feeding behavior $(P=0.004)$ than did LA-treated calves in the 8-h period (Table 4; Figure 3). The LAtreated calves exhibited more statue standing and more head turning in the 3 -h PC period than did LA+FMtreated calves $(P=0.002$; Figure 3$)$.

\section{DISCUSSION}

The goal of the study reported here was to determine if administering FM, LA, or LA+FM 20 min before surgical castration would reduce responses suggestive of pain or stress in young dairy calves. Castration of 2- to 3-mo-old Holstein calves using a Newberry knife and Henderson castrating tool, with or without supplemental anesthetic or analgesic agents, did not significantly affect feed intake or BW gain in the $10 \mathrm{~d}$ following castration compared with SC controls. However, calves castrated without anesthetic or analgesic agents experienced an immediate increase in plasma cortisol concentration that persisted for $60 \mathrm{~min}$ and exhibited several behavioral changes for at least $8 \mathrm{~h}$. Administering LA alone did not ameliorate the cortisol responses following 

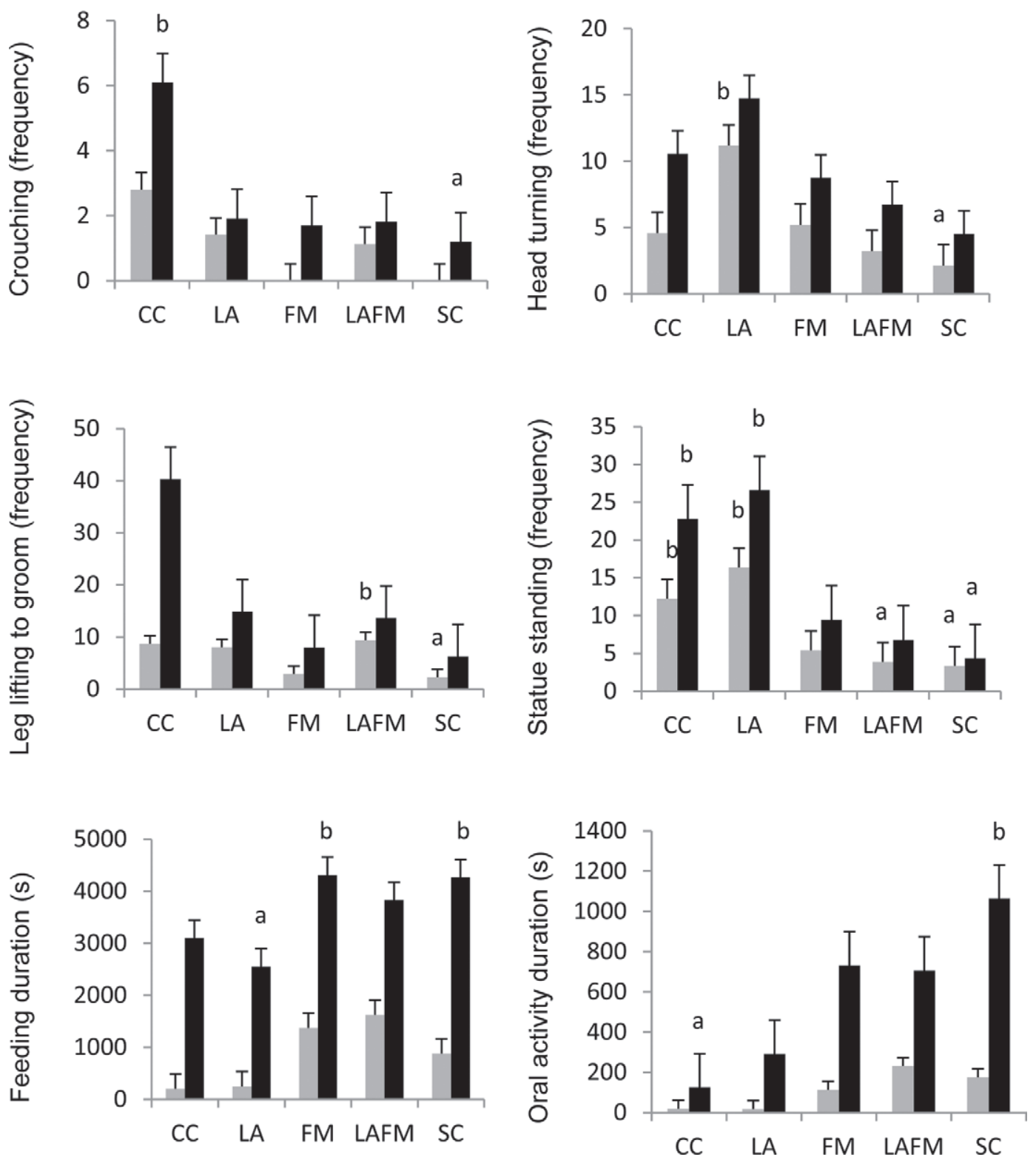

Figure 3. Comparison of select behaviors during the 3-h (gray bars) and 8-h (black bars) periods after castration for calves castrated surgically without anesthesia or analgesia (CC) or administered a local anesthetic agent (LA), an i.v. injection of flunixin meglumine (FM) or a combination of both treatments (LAFM) before castration $(\mathrm{n}=6$ /group). The SC calves were sham-castrated controls $(\mathrm{n}=6)$. Values expressed as least squares means \pm SE. Values with different letters for the 3- or 8-h period are significantly different $(P<0.005$ after Bonferroni adjustment).

castration and was associated with a second transient increase in cortisol. The LA-treated calves also had a higher frequency of head turning, statue standing, tail flicking, and posture shifts and less feeding behavior compared with SC controls. These findings suggest that LA alone was not effective at reducing castrationassociated pain or stress. Administering LA+FM prevented an increase in plasma cortisol concentration after castration. Significant behavioral differences were not detected between FM- or LA+FM-treated calves and SC controls, with the exception of more leg lifting to groom and scrotal licking in LA+FM-treated calves. These findings suggest that FM alone was somewhat effective in mitigating pain in surgically castrated 2- to 3 -mo-old dairy calves, with LA+FM being the most effective of the 3 drug protocols.

\section{Study Design}

There are no direct, validated measures of pain in calves. Indirect measures used in castration studies include changes in circulating concentrations of neuro- 
Table 4. Frequency of behaviors (number; least squares means with range in parentheses) observed in the 3- or 8-h period following castration in 30 calves castrated surgically without anesthesia or analgesia (CC) or administered a local anesthetic agent (LA) with or without an i.v. injection of flunixin meglumine (FM) before castration ( $\mathrm{n}=6$ /group)

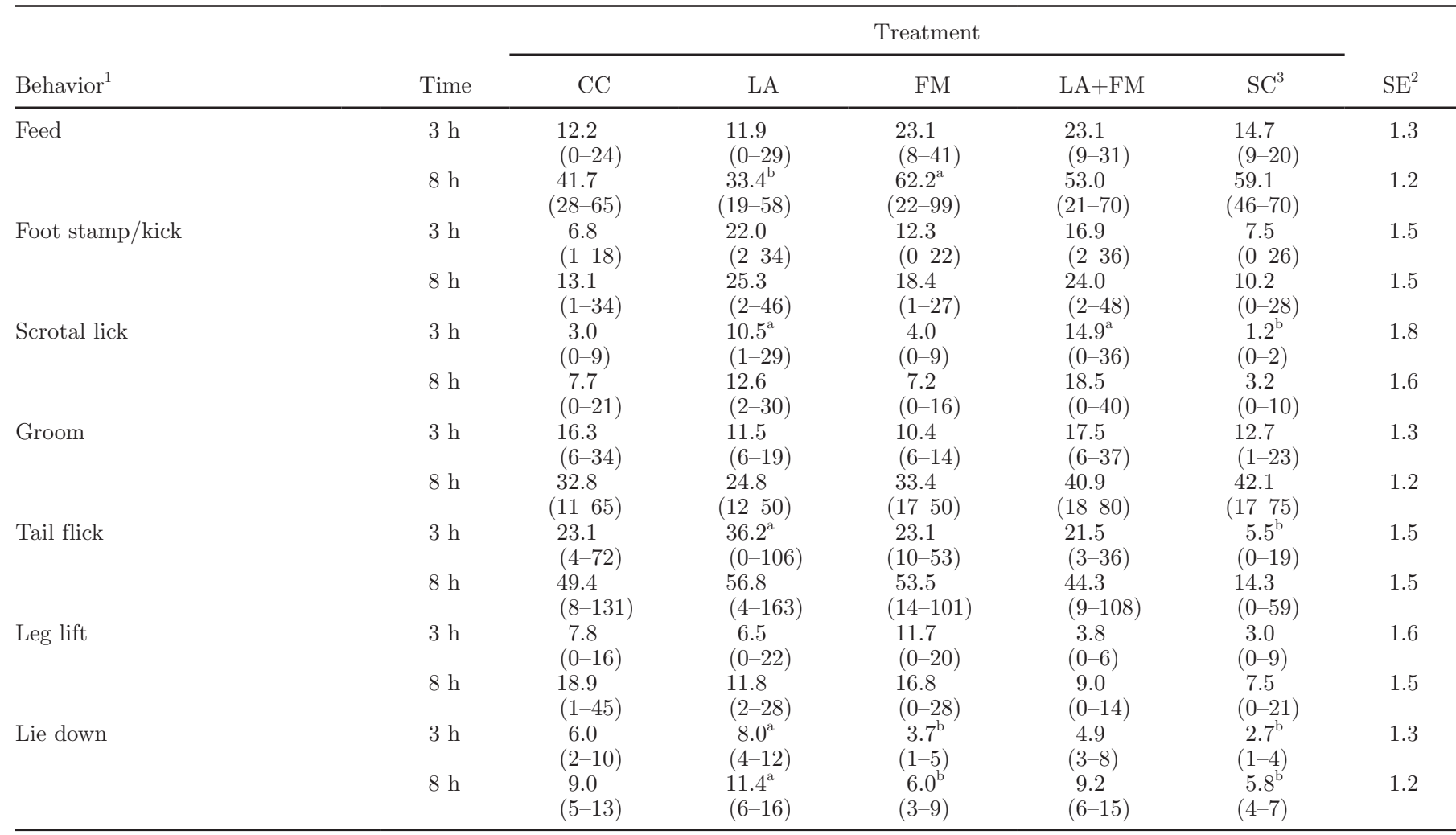

${ }^{\mathrm{a}, \mathrm{b}}$ Values with different superscripts within a row are significantly different $(P<0.005$ after Bonferroni adjustment).

${ }^{1}$ Behaviors are defined in Table 1.

${ }^{2}$ Standard error for the frequency estimate.

${ }^{3} \mathrm{SC}=$ sham-castrated controls $(\mathrm{n}=6)$.

endocrine and inflammatory markers, such as cortisol (Stafford and Mellor, 2005a), substance-P (Coetzee and Apley, 2008; Coetzee et al., 2008), immune factors (Chase et al., 1995; Ting et al., 2003a), epinephrine/ norepinephrine (Stewart et al., 2010), and acute phase proteins (Ting et al., 2003a), with cortisol used most frequently. Unfortunately, such indicators are affected by factors other than pain and require frequent sampling to capture transient or episodic changes. Behavioral changes are also used as indirect indicators of pain, but studies lack standardization with respect to definition of behaviors, frequency and duration of monitoring, and interpretation of results. More objective indirect techniques for quantifying pain include the use of force meters (Schwartzkopf-Genswein et al., 1998), vocalization measures (Rust et al., 2007), eye temperature (Stewart et al., 2010), stride length (Currah et al., 2009), heart rate (Stewart et al., 2010), and activity using pedometers (Currah et al., 2009) and accelerometers (White et al., 2008). Because no single optimal measure of pain exists, using several dif- ferent measures can facilitate interpretation of study results. For this reason, we evaluated plasma cortisol concentration, short-term performance parameters, and behavior in the current study.

To minimize the effect of pen location, we stratified treatments by pen so that calves from each treatment group experienced each location. By castrating calves in the same order as their pen numbers, we ensured that all groups contained calves that were castrated first, second, third, fourth, and fifth; this minimized confounding due to noise and human activity. Having a single person (H.B.W.) perform the castrations and administer the lidocaine kept procedures as consistent as possible. This person was observed by at least one other investigator and videotaped while administering lidocaine and castrating the calves to document the consistency of technique. Using video for behavioral observation avoided an effect of observer presence; however, study personnel undoubtedly influenced behavior during cortisol sampling; preplacement of i.v. catheters minimized the amount of time and restraint required 
Table 5. Total duration of behaviors (seconds; geometric means with range in parentheses) observed in the 3- or 8-h period following castration in 30 calves castrated surgically without anesthesia or analgesia (CC) or administered a local anesthetic agent (LA) with or without an i.v. injection of flunixin meglumine (FM) before castration ( $\mathrm{n}=6 /$ group)

\begin{tabular}{|c|c|c|c|c|c|c|c|}
\hline \multirow[b]{2}{*}{ Behavior } & \multirow[b]{2}{*}{ Time } & \multicolumn{5}{|c|}{ Treatment } & \multirow[b]{2}{*}{$P$-value } \\
\hline & & $\mathrm{CC}$ & LA & FM & $\mathrm{LA}+\mathrm{FM}$ & $\mathrm{SC}^{2}$ & \\
\hline \multirow[t]{2}{*}{ Normal lying } & $3 \mathrm{~h}$ & $\begin{array}{l}518 \\
\quad(0-6,821)\end{array}$ & $\begin{array}{l}1,998 \\
(1,152-5,412)\end{array}$ & $\begin{array}{l}1,415 \\
(358-3,129)\end{array}$ & $\begin{array}{l}2,166 \\
(762-6,101)\end{array}$ & $\begin{array}{l}3,936 \\
(2,249-5,048)\end{array}$ & 0.24 \\
\hline & $8 \mathrm{~h}$ & $\begin{array}{l}2,810 \\
(150-11,039)\end{array}$ & $\begin{array}{l}5,252 \\
(2,441-13,589)\end{array}$ & $\begin{array}{l}3,293 \\
(613-6,997)\end{array}$ & $\begin{array}{l}6,341 \\
(1,688-15,999)\end{array}$ & $\begin{array}{l}9,738 \\
(7,188-14,525)\end{array}$ & 0.15 \\
\hline \multirow[t]{2}{*}{ Abnormal lying } & $3 \mathrm{~h}$ & $\begin{array}{l}2,941 \\
(557-6,946)\end{array}$ & $\begin{array}{l}2,561 \\
(1,258-5,354)\end{array}$ & $\begin{array}{l}3,103 \\
(646-5,529)\end{array}$ & $\begin{array}{l}1,391 \\
(762-6,101)\end{array}$ & $\begin{array}{l}960 \\
(0-4,820)\end{array}$ & 0.76 \\
\hline & $8 \mathrm{~h}$ & $\begin{array}{l}10,772 \\
(7,797-16,674)\end{array}$ & $\begin{array}{l}9,300 \\
(6,978-15,081)\end{array}$ & $\begin{array}{l}10,254 \\
(5,772-15,013)\end{array}$ & $\begin{array}{l}6,904 \\
(2,306-12,845)\end{array}$ & $\begin{array}{l}1,840 \\
\quad(0-12,805)\end{array}$ & 0.40 \\
\hline \multirow[t]{2}{*}{ Normal standing } & $3 \mathrm{~h}$ & $\begin{array}{l}3,212 \\
(2,223-5,983)\end{array}$ & $\begin{array}{l}2,784 \\
(275-7872)\end{array}$ & $\begin{array}{l}4,414 \\
(1,805-8,936)\end{array}$ & $\begin{array}{l}5,013 \\
(3,619-6,886)\end{array}$ & $\begin{array}{l}3,018 \\
(1,510-5,311)\end{array}$ & 0.42 \\
\hline & $8 \mathrm{~h}$ & $\begin{array}{l}9,556 \\
(6,402-13,900)\end{array}$ & $\begin{array}{l}9,364 \\
(4,007-18,525)\end{array}$ & $\begin{array}{l}12,139 \\
(7,001-21,445)\end{array}$ & $\begin{array}{l}11,703 \\
(9,258-18,204)\end{array}$ & $\begin{array}{l}10,233 \\
(5,326-13,834)\end{array}$ & 0.70 \\
\hline \multirow[t]{2}{*}{ Abnormal standing } & $3 \mathrm{~h}$ & $\begin{array}{l}452 \\
\quad(0-2,652)\end{array}$ & $\begin{array}{l}290 \\
(0-4,151)\end{array}$ & $\begin{array}{l}57 \\
(0-1,068)\end{array}$ & $\begin{array}{l}25 \\
(0-1,484)\end{array}$ & $\begin{array}{l}37 \\
(0-460)\end{array}$ & 0.087 \\
\hline & $8 \mathrm{~h}$ & $\begin{array}{l}1,647 \\
(327-8,799)\end{array}$ & $\begin{array}{r}1,294 \\
(345-5,756)\end{array}$ & $\begin{array}{r}105 \\
(0-2,071)\end{array}$ & $\begin{array}{l}71.1 \\
(0-1,729)\end{array}$ & $\begin{array}{l}230 \\
(90-460)\end{array}$ & 0.011 \\
\hline \multirow[t]{2}{*}{ Feed lag } & $3 \mathrm{~h}$ & $\begin{array}{l}8.7 \\
(0-260)\end{array}$ & $\begin{array}{l}9.73 \\
(0-40)\end{array}$ & $\begin{array}{l}24 \\
(15-50)\end{array}$ & $\begin{array}{l}6.2 \\
(0-60)\end{array}$ & $\begin{array}{l}25 \\
(0-245)\end{array}$ & 0.36 \\
\hline & $8 \mathrm{~h}$ & $\begin{array}{l}14 \\
(1.9-260)\end{array}$ & $\begin{array}{l}20 \\
(0.9-88)\end{array}$ & $\begin{array}{l}35 \\
(15.2-113.5)\end{array}$ & $\begin{array}{l}11 \\
(0.1-156.5)\end{array}$ & $\begin{array}{l}33 \\
(0.2-245)\end{array}$ & 0.67 \\
\hline
\end{tabular}

${ }_{\overline{3}}^{\mathrm{a}, \mathrm{b}}$ Values with different superscripts within a row are significantly different $(P<0.005$ after Bonferroni adjustment).

$\quad{ }^{1} P$-value for the main effect of treatment

${ }^{2} \mathrm{SC}$ group $=$ sham-castrated controls $(\mathrm{n}=6)$. 
to obtain those samples. Video capture allowed a single observer to view the entire uninterrupted 8-h PC period for each calf and to quantify a range of behaviors. This would not have been possible by direct observation of the calves and allowed more comprehensive analysis than in other published castration studies. The person who quantified behaviors (H.B.W.) also performed the treatments (this was his MS project). To minimize the risk of bias, videos were not reviewed until 6 mo after the study ended, and no indicators of treatment group were marked on calves or pens. The observer did not refer to treatment records until after behavior analysis was completed and was not able to tell the surgical status (intact vs. castrated) of calves from the video. In other words, behavior was categorized by an investigator who was unlikely to be aware of treatment assignment.

We chose to use the Newberry knife and Henderson castrating tool in an effort to ensure uniformity of castration technique by minimizing subtle operator-associated variation. The Newberry knife makes an incision of a consistent size in the scrotum. The Henderson tool exerts a similar twisting force on the spermatic cords of each animal. Both of these instruments have been used in previous castration studies (Coetzee et al., 2007, 2008). A recent survey by Coetzee et al. (2010) found that approximately $15 \%$ of the 189 veterinarians surveyed used the Henderson tool in 90- to $270-\mathrm{kg}$ dairy calves. We found the tool easy to use in 2- to 3-mo-old calves, although surgical methods involving manual traction to sever the spermatic cords are more commonly used in calves of this age group (Coetzee et al., 2010). No animals in the study reported here experienced postsurgical hemorrhage, wound infection, or systemic illness after castration.

To achieve local anesthesia, we administered lidocaine directly into both testes and allowed time for the lidocaine to diffuse into the spermatic cords. We also injected lidocaine subcutaneously around the spermatic cords at the scrotal neck to reduce nociception in the scrotal skin during incision and provide anesthesia in the area where most subcutaneous tissue stripping occurs. The relatively large volume $(25 \mathrm{~mL}$; approximately $5-7$ $\mathrm{mg} / \mathrm{kg}$ of BW) of lidocaine used was chosen to achieve a complete ring block and promote adequate diffusion while still remaining in a safe dose range. Because 5 $\mathrm{mL}$ of lidocaine was injected into the testicles that were surgically removed, the effective net lidocaine dose was $20 \mathrm{~mL}$ or approximately $5 \mathrm{mg} / \mathrm{kg}$ of BW. This dose rate was based on a previous study in calves that indicated epidural administration of lidocaine at $8 \mathrm{mg} / \mathrm{kg}$ BW was safe (Meyer et al., 2007) and on another study in ewes that stated subcutaneous injection of lidocaine at $10 \mathrm{mg} / \mathrm{kg}$ of BW was safe (Scarratt and Troutt, 1986).
Results of the current study indicate that LA alone did not reduce the cortisol response to castration and suggest that lidocaine administration may have resulted in tissue irritation or inflammation. Had responses in the LA group been a consequence of lidocaine toxicity, we would have expected similar findings in calves in the LA+FM group, but those calves had no increase in plasma cortisol concentration and fewer behaviors that differed from SC controls.

An increase in heart rate was reported previously when calves were administered lidocaine subcutaneously and intratesticularly (Stewart et al., 2010). Thornton and Waterman-Pearson (1999) observed that young lambs exhibited an increase in scrotal pain responses when administered lidocaine, whether or not they were castrated. Fisher et al. (1996) measured a larger scrotal circumference 35 d after clamp castration when calves were administered lidocaine, compared with calves castrated without lidocaine or noncastrated controls. In contrast, Stafford et al. (2002) and Stewart et al. (2010) observed no increase in cortisol concentrations in 2- to 4-mo-old noncastrated calves administered lidocaine directly into each testis and subcutaneously at the distal end of the scrotum, with or without subcutaneous infiltration at the neck of the scrotum. It is possible that LA-treated calves in the study reported here may have responded differently had we injected a smaller volume of lidocaine subcutaneously. Alternatively, the responses we observed may have been due to the surgical method used or to injecting lidocaine into the testes rather than the spermatic cords. Twisting and severing of the spermatic cords by the Henderson tool may have stimulated nociceptors proximal to the site of lidocaine action. Such a theory was proposed to explain the poor efficacy of LA for reducing responses to surgical castration in 2- to 4-mo-old calves when the testes were removed using traction (Stafford and Mellor, 2005a). Including a third control group in the study reported here to account for the effects of lidocaine administration without castration would have been ideal, but was not done because of limited resources. Our findings should not be extrapolated to other lidocaine administration regimens or castration techniques.

We chose to measure feed intake and BW gain in the study reported here because they are clinically relevant, easily obtained, objective parameters of health and well-being. Based on National Research Council growth statistics for dairy calves (NRC, 2001), we expected calves to gain at least 5.9 to $6.4 \mathrm{~kg}$ of BW during the 10-d PC period. Average BW gain was $8.4 \mathrm{~kg}$, with no significant differences in feed intake or BW gain among treatment groups. The absence of significant differences in feed intake and BW gain was not surprising, given the small size of the treatment groups, the substantial 
individual variability among calves, and findings of previous studies. Stafford et al. (2002) reported no differences in BW gain during a 90-d assessment of 2- to 4-mo-old dairy calves castrated by a variety of techniques, with or without anesthetic or analgesic agents. Molony et al. (1995) found no differences in BW gain during a 35-d assessment of 1-wk-old dairy calves castrated using 4 methods, including surgical castration. Despite the expected variation among calves and results of previous studies, we felt it was important to quantify and report feed intake and BW gain. Had we observed significant differences among treatment groups, this would have been notable and worthy of reporting and further investigation. The lack of significant differences in our small study should not be equated to the absence of a treatment effect; a larger study would be needed to achieve sufficient power given the variation among animals.

Despite the absence of significant differences in 10-d feed intake or BW gain among treatment groups, we did observe an effect of treatment on oral activity and feeding behavior in the first $8 \mathrm{~h}$ after castration (Figure 3). Robertson et al. (1994) reported that dairy calves castrated at 21 or $42 \mathrm{~d}$ of age spent less time eating compared with noncastrated controls during a 3 -h monitoring period. We did not observe such an effect in calves castrated without drugs, although those calves exhibited less oral activity (other than feeding behavior) in the 8-h PC period compared with SC controls. We did observe less feeding behavior in LAtreated calves in the 8-h PC period than in SC controls. This was not the case when calves were administered LA+FM, which suggests it may have been a result of inflammation or pain that was mitigated by FM, rather than a pharmacological effect of the lidocaine.

We obtained baseline $(-20 \mathrm{~min})$ plasma cortisol samples as soon as calves were moved to the treatment chute, immediately before administering drugs or placebos. Although calves could not be considered resting at this point, the relocation process took $<2 \mathrm{~min}$, which is shorter than the expected lag time for plasma cortisol response to a stressor (Lay et al., 1992; Kirschbaum and Hellhammer, 2000). Baseline plasma cortisol concentrations $(<10.3 \mathrm{ng} / \mathrm{mL})$ did not differ among treatment groups and were similar in magnitude to those reported by Coetzee et al. (2010), Stewart et al. (2010), and Bergamasco et al. (2011). The interassay CV for the plasma cortisol assay we used was moderately high, although similar to that of Earley and Crowe (2002), who reported interassay CV ranging from 10.8 to $17.5 \%$ using a RIA.

We obtained time-zero (0 min) plasma cortisol samples immediately after castration or sham castration, which took $\leq 3$ min to perform. Therefore, we believe the time-zero samples reflect predominantly the stress or pain associated with drug administration and restraint, rather than with castration. However, the fact that plasma cortisol was already above baseline at time zero in calves castrated without drugs suggests that immediate castration-associated pain may have influenced the time-zero results.

Elevated plasma cortisol concentrations have been observed for at least $6 \mathrm{~h}$ after surgical castration of dairy cattle 6 mo of age and older (Cohen et al., 1990; Fisher et al., 1996). More transient $(<3 \mathrm{~h})$ cortisol responses are typically observed in younger calves (Molony et al., 1995; Stafford et al., 2002; Bergamasco et al., 2011). Behavioral changes are most apparent in the first $3 \mathrm{~h}$ PC (Molony et al., 1995; Ting et al., 2003a). We chose to monitor plasma cortisol concentration and behavior for $8 \mathrm{~h} \mathrm{PC}$ to enable us to detect delayed responses that might occur after lidocaine activity dissipates (Stafford and Mellor, 2005a) or FM concentration begins to decline (Landoni et al., 1995). However, we also analyzed data for the first $3 \mathrm{~h} \mathrm{PC}$ to increase the likelihood of identifying differences among treatment groups. A longer study would be needed to investigate how long behavioral differences persist between calves castrated without drugs or with LA alone and SC controls, and to assess the effect, if any, of continued decline in FM concentration.

The plasma cortisol profile we observed in calves castrated without anesthetic or analgesic agents is consistent with most previously published findings (Molony et al., 1995; Fisher et al., 1996; Earley and Crowe, 2002; Stafford et al., 2002; Stafford and Mellor, 2005a). Failure of LA to mitigate the cortisol response to castration in the study reported here is in contrast to the findings of Fisher et al. (1996) and Earley and Crowe (2002), who reported that older calves given LA before surgical castration had lower mean or maximum plasma cortisol concentrations in the first $2 \mathrm{~h}$ postoperatively than did calves castrated without LA. Secondary (delayed) cortisol spikes occurred in LAtreated calves in both of those studies, as well as in the current study. The spike occurred at $120 \mathrm{~min}$ in the study reported here, which is after the anesthetic effect of lidocaine should have dissipated, based on its short duration of action (Stafford and Mellor, 2005a). Secondary cortisol spikes may be a response to discomfort associated with tissue inflammation after lidocaine dissipates (Stafford and Mellor, 2005a), which would explain why they were not observed in calves administered LA+FM in the study reported here. Administering LA+FM completely prevented an increase in plasma cortisol concentration after castration. This is consistent with the study by Earley and Crowe (2002), in which administering ketoprofen + 
LA virtually eliminated the plasma cortisol response to surgical castration in dairy calves.

Mean Cmax plasma cortisol values for calves in the study reported here (21 to $37 \mathrm{ng} / \mathrm{mL}$ ) were in line with those reported in a review by Stafford and Mellor (2005a). Substantial variation in Tmax, Cmax, and AUC values among individual calves hindered our ability to detect a treatment effect. Despite marked numerical differences in mean values among treatment groups, the only significant difference was a higher $\mathrm{AUC}_{200}$ in calves castrated without drugs than in SC controls. However, despite the relatively small sample size and substantial variation among calves, we were able to identify significant treatment and treatment $\times$ time effects on mean plasma cortisol concentration. More between-group differences in cortisol parameters may have been evident with a larger sample size.

Only a small number of behavioral changes were identified between calves castrated without drugs and $\mathrm{SC}$ controls in the study reported here, which hindered our ability to identify an effect of drug treatment. We observed a greater frequency of crouching in calves castrated without anesthetic or analgesic agents than in SC controls during the 8-h PC periods. Molony et al. (1995) reported an increase in restlessness score, which included crouching, in 1-wk-old dairy calves castrated using bloodless castration techniques. Robertson et al. (1994) reported increased restlessness scores that included crouching in 6-, 21- and 42-d-old calves castrated with rubber rings but not surgically castrated calves. Stewart et al. (2008) observed crouching in 5to 7 -wk-old dairy calves after disbudding but not in nondisbudded controls. Crouching may be more powerful as a single indicator of discomfort rather than as a component of a more complex restlessness score.

We observed a greater frequency of head-turning in calves that received LA alone before castration than in $\mathrm{SC}$ controls during the first $3 \mathrm{~h}$ PC. Head-turning is believed to be similar to flank-watching in horses with colic and has been observed in lambs and calves following castration (Molony et al., 1993, 1995; Boesch et al., 2008; Marti et al., 2010). Boesch et al. (2008) reported an increased frequency of head-turning in 2- to 7-d-old calves on the day of bloodless castration compared with the day before, irrespective of whether calves received LA. Marti et al. (2010) observed a tendency for more frequent head-turning $14 \mathrm{~d}$ after rubber ring castration of 3-mo-old calves compared with noncastrated controls. In the current study, the increase in head-turning in the LA group may have been due to pain or inflammation from lidocaine administration or its presence in the scrotal tissues, because head-turning frequency was not different in calves administered LA $+\mathrm{FM}$ than in SC controls.
Calves administered LA alone before castration exhibited more lying down events compared with SC controls and calves administered FM alone in the current study. An increase in up and down events reflects restlessness and has been postulated to indicate castration-associated pain (Molony et al., 1995).

Both the LA- and LA+FM-treated calves tended to have higher frequencies of leg lifting to groom and scrotal licking in the 3- and 8-h PC periods, with significant increases noted during the first $3 \mathrm{~h}$. This behavior may have been a response to inflammation or irritation resulting from lidocaine administration or an aborted attempt to lick at the castration site; both behaviors require lifting and extension of the hind leg. Boesch et al. (2008) identified a tendency for more scrotal licking in clamp-castrated calves administered LA compared with those castrated without LA.

We observed a higher frequency of statue standing during the 8-h PC period in calves castrated without drugs or with LA alone, compared with SC controls. Administering FM along with LA mitigated the increase in statue standing during the first $3 \mathrm{~h} \mathrm{PC}$. Robertson et al. (1994) reported a longer duration of statue standing in 42-d-old surgically castrated calves than in noncastrated controls during the first $3 \mathrm{~h}$ PC. Molony et al. (1995) found a higher duration of statue standing in 1-wk-old surgically castrated calves compared with control calves during the same postsurgical period. Fell et al. (1986) observed that most 4- to 11-wk-old surgically castrated dairy calves stood motionless for the first 1 to $2 \mathrm{~h}$ postcastration. Currah et al. (2009), with the use of pedometers, observed that 3-mo-old beef calves that were surgically castrated without drugs took significantly fewer steps than those administered an epidural, or FM, or both before castration. Using accelerometers, White et al. (2008), found that surgically castrated calves spent significantly more time standing after castration than before castration. Adopting an immobile stance following castration may prevent or reduce stimulation of hyperalgesic tissues, thereby minimizing pain (Molony and Kent, 1997).

Our findings suggest that administering FM alone before surgical castration may shorten the cortisol response and avoid some of the behavioral changes observed in calves castrated without drugs or with LA alone. Benefits of administering NSAID alone before castration have been reported for ketoprofen (Earley and Crowe, 2002; Ting et al., 2003a,b) and sodium salicylate (Coetzee et al., 2007). Ketoprofen alone was more effective than LA in ameliorating the cortisol response to castration (Earley and Crowe, 2002). Ting et al. (2003a) observed that ketoprofen alone mitigated overall plasma cortisol response to surgical castration, as well as the higher incidence of abnormal standing 
seen in nonmedicated calves. Ketoprofen attenuated the plasma cortisol response following clamp castration more effectively than did LA or a lidocaine-xylazine epidural, and was more effective than LA in minimizing behavioral changes during the first $6 \mathrm{~h}$ after castration (Ting et al., 2003b).

Few published studies have investigated the effectiveness of FM as an analgesic agent for calf castration, and studies vary with regards to dosage and route of administration. Stilwell et al. (2008) reported a decrease in plasma cortisol concentration $6 \mathrm{~h}$ after clamp castration when a lidocaine epidural and subcutaneous FM $(2.2 \mathrm{mg} / \mathrm{kg})$ were both administered to 5 - to 6 -mo-old dairy calves. Currah et al. (2009) concluded that i.v. FM $(2.2 \mathrm{mg} / \mathrm{kg})$ combined with a lidocaine epidural effectively controlled pain for 8 to $12 \mathrm{~h}$ postcastration in 3-mo-old surgically castrated dairy calves, based on an increase in stride length and number of steps taken. González et al. (2010) band-castrated 200-dold beef calves with and without a xylazine epidural and i.v. FM $(1.1 \mathrm{mg} / \mathrm{kg})$ and found no difference in salivary cortisol concentrations between noncastrated controls and medicated banded calves for the 14-d trial, and a lower salivary cortisol concentration for up to $4 \mathrm{~h}$ postcastration in the medicated calves compared with the nonmedicated calves. In contrast, Marti et al. (2010), using i.m. FM (3 mg/kg) in conjunction with LA, found increases in some behaviors and reduced performance but no changes in serum cortisol in 3-mo-old Holstein calves castrated using rubber rings compared with intact control calves. Booker et al. (2009) castrated 229- to $312-\mathrm{kg}$ beef bulls surgically or by banding with or without administering i.v. FM $(2.2$ $\mathrm{mg} / \mathrm{kg}$ ) and a xylazine epidural, and observed no differences in animal health or feedlot performance between the medicated and nonmedicated bulls. None of these published studies included a group of castrated animals that received FM alone. Further study is warranted to determine what effect, if any, the short plasma half-life of FM ( 4 to $8 \mathrm{~h}$ ) has on its effectiveness as an analgesic for surgical castration once its effects wane. This is a potential limitation of the usefulness of FM when given according to label by the i.v. route.

\section{CONCLUSIONS}

We conclude that administering lidocaine alone as a subcutaneous ring block around the spermatic cords and into the testes does not sufficiently aid in mitigating signs of pain or stress when castrating 2- to 3-moold dairy calves with a Newberry knife and Henderson castration tool. Based on cortisol responses, LA+FM appears to be an appropriate analgesic regimen, but a larger study is needed to more thoroughly investigate effects of LA on behavior, such as the increase in leg lifting to groom that we observed in LA+FM-treated calves in the first $3 \mathrm{~h} \mathrm{PC}$. Intravenous administration of FM alone is easier to accomplish and safer for the operator than administering LA+FM, but it does not desensitize the surgical site and did not completely eliminate the cortisol response to surgical castration in the study reported here.

\section{ACKNOWLEDGMENTS}

This study was funded, in part, by a grant from the American Association of Bovine Practitioners (Auburn, AL). We thank the University of Illinois Dairy Research Unit (Champaign-Urbana) for the use of their facilities.

\section{REFERENCES}

AVMA (American Veterinary Medical Association). 2012. Welfare implications of castration of cattle. Accessed Jul. 31, 2012. https:// www.avma.org/KB/Resources/Backgrounders/Documents/ castration-cattle-bgnd.pdf.

AVMA (American Veterinary Medical Association). 2008. Castration and dehorning of cattle. Accessed Jul. 31, 2012. https:// www.avma.org/KB/Policies/Pages/Castration-and-Dehorning-ofCattle.aspx.

Arave, C. W., and J. L. Albright. 1997. Animal Welfare Issues: Dairy. USDA Animal Welfare Issues Compendium. Accessed Dec. 5, 2010. http://www.nalusda.gov/awic/pubs/97issues.htm.

Bergamasco, L., J. F. Coetzee, R. Gehring, L. Murray, T. Song, and R. A. Mosher. 2011. Effect of intravenous sodium salicylate administration prior to castration on plasma cortisol and electroencephalography parameters in calves. J. Vet. Pharmacol. Ther. $34: 565-576$.

Boesch, D., A. Steiner, L. Gygax, and M. Stauffacher. 2008. Burdizzo castration of calves less than 1-week old with and without local anaesthesia: Short-term behavioural responses and plasma cortisol levels. Appl. Anim. Behav. Sci. 114:330-345.

Booker, C. W., S. M. Abutarbush, O. C. Schunicht, C. M. Pollock, T. Perrett, B. K. Wildman, S. J. Hannon, T. J. Pittman, C. W. Jones, G. J. Jim, and P. S. Morley. 2009. Effect of castration timing, technique and pain management on health and performance of young feedlot bulls in Alberta. Bovine Pract. 43:1-11.

Chase, C. C., R. E. Larsen Jr., R. D. Randel, A. C. Hammond, and E. L. Adams. 1995. Plasma cortisol and white blood cell responses in different breeds of bulls: A comparison of two methods of castration. J. Anim. Sci. 73:975-980.

Coetzee, J. F., and M. D. Apley. 2008. Pharmacokinetic-pharmacodynamic modeling of analgesic drugs in beef cattle. AABP Proc. 41:29-34.

Coetzee, J. F., R. Gehring, A. C. Bettenhausen, B. V. Lubbers, S. E. Toerber, D. U. Thomson, B. Kukanich, and M. D. Apley. 2007. Attenuation of acute plasma cortisol response in calves following intravenous sodium salicylate administration prior to castration. J. Vet. Pharmacol. Ther. 30:305-313.

Coetzee, J. F., B. L. Lubbers, S. E. Toerber, R. Gehring, D. U. Thomson, B. J. White, and M. D. Apley. 2008. Plasma concentrations of substance $\mathrm{P}$ and cortisol in beef calves after castration or simulated castration. Am. J. Vet. Res. 69:751-762.

Coetzee, J. F., A. L. Nutsch, L. A. Barbur, and R. M. Bradburn. 2010. A survey of castration methods and associated livestock management practices performed by bovine veterinarians in the United States. BMC Vet. Res. 6:12. http://dx.doi.org/10.1186/17466148-6-12 
Cohen, R. D. H., B. D. King, L. R. Thomas, and E. D. Janzen. 1990 Efficacy and stress of chemical versus surgical castration of cattle. Can. J. Anim. Sci. 70:1063-1072.

Coxe, S., S. G. West, and L. S. Aiken. 2009. The analysis of count data: A gentle introduction to Poisson regression and its alternatives. J. Pers. Assess. 91:121-136.

Currah, J. M., S. H. Hendrick, and J. M. Stookey. 2009. The behavioral assessment and alleviation of pain associated with castration in beef calves treated with flunixin meglumine and caudal lidocaine epidural anesthesia with epinephrine. Can. Vet. J. 50:375-382.

Earley, B., and M. A. Crowe. 2002. Effects of ketoprofen alone or in combination with local anesthesia during the castration of bull calves on plasma cortisol, immunological, and inflammatory responses. J. Anim. Sci. 80:1044-1052.

Faulkner, D. B., T. Eurell, W. J. Tranquilli, R. S. Ott, M. W. Ohl, G. F. Cmarik, and G. Zinn. 1992. Performance and health of weanling bulls after butorphanol and xylazine administration at castration. J. Anim. Sci. 70:2970-2974.

Fell, L. R., R. Wells, and D. A. Shutt. 1986. Stress in calves castrated surgically or by the application of rubber rings. Aust. Vet. J. $63: 16-18$

Fisher, A. D., M. A. Crowe, M. E. Alonso de la Varga, and W. J. Enright. 1996. Effect of castration method and the provision of local anesthetic on plasma cortisol, scrotal circumference, growth, and feed intake of bull calves. J. Anim. Sci. 74:2336-2343.

Fisher, A. D., T. W. Knight, G. P. Cosgrove, A. F. Death, C. B. Anderson, D. M. Duganzich, and L. R. Matthews. 2001. Effects of surgical or banding castration on stress responses and behaviour of bulls. Aust. Vet. J. 79:279-284.

González, L. A., K. S. Schwartzkopf-Genswein, N. A. Caulkett, E. Janzen, T. A. McAllister, E. Fierheller, A. L. Schaefer, D. B. Haley J. M. Stookey, and S. Hendrick. 2010. Pain mitigation after band castration of beef calves and its effects on performance, behavior, Escherichia coli, and salivary cortisol. J. Anim. Sci. 88:802-810.

Kirschbaum, C., and D. H. Hellhammer. 2000. Salivary cortisol. Pages 279-383 in Encyclopedia of Stress. Vol. 3. G. Fink, ed. Academic Press, San Diego, CA.

Landoni, M. F., F. M. Cunningham, and P. Lees. 1995. Determination of pharmacokinetics and pharmacodynamics of flunixin in calves by use of pharmacokinetic/pharmacodynamic modeling. Am. J. Vet. Res. 56:786-794.

Lay, D. C. Jr., T. H. Friend, C. L. Bowers, K. K. Grissom, and O. C Jenkins. 1992. A comparative physiological and behavioral study of freeze and hot-iron branding using dairy cows. J. Anim. Sci. 70:1121-1125.

Marti, S., A. Velarde, J. L. de la Torre, A. Bach, A. Aris, A. Serrano, X. Manteca, and M. Devant. 2010. Effect of ring castration with local anesthesia in Holstein calves at 3 months of age on welfare indicators. J. Anim. Sci. 88:2789-2796.

Meyer, H., A. Starke, W. Kehler, and J. Rehage. 2007. High caudal epidural anaesthesia with local anaesthetics or $\alpha_{2}$-agonists in calves. J. Vet. Med. A Physiol. Pathol. Clin. Med. 54:384-389.

Molony, V., and J. E. Kent. 1997. Assessment of acute pain in farm animals using behavioural and physiological measurements. J. Anim. Sci. 75:266-272.

Molony, V., J. E. Kent, and I. S. Robertson. 1993. Behavioral responses of lambs of three ages in the first three hours after three methods of castration and tail docking. Res. Vet. Sci. 55:236-245.

Molony, V., J. E. Kent, and I. S. Robertson. 1995. Assessment of acute and chronic pain after different methods of castration of calves. Appl. Anim. Behav. Sci. 46:33-48.

NRC. 2001. Nutrient Requirements of Dairy Cattle. 7th rev. ed. National Academies Press, Washington, DC.

NFACC (National Farm Animal Care Council). 2009. Code of practice for the care and handling of dairy cattle: A review of scientific research on priority issues. Accessed Jul. 31, 2012. http://www. nfacc.ca/pdfs/codes/scientists-committee-reports/Dairy\%20Scientists\%20Committee\%20Report.pdf.

Robertson, I. S., J. E. Kent, and V. Molony. 1994. Effects of different methods of castration on behaviour and plasma cortisol in calves of three ages. Res. Vet. Sci. 56:8-17.
Rust, R. L., D. U. Thomson, G. H. Loneragan, M. D. Apley, and J. C. Swanson. 2007. Effect of different castration methods on growth performance and behavior responses of postpubertal beef bulls. Bovine Pract. 41:111-118.

Scarratt, W. K., and H. F. Troutt. 1986. Iatrogenic lidocaine toxicosis in ewes. J. Am. Vet. Med. Assoc. 188:184-185.

Schwartzkopf-Genswein, K. S., J. M. Stookey, T. G. Crowe, and B. M. A. Genswein. 1998. Comparison of image analysis, exertion force, and behaviour measurements for use in the assessment of beef cattle responses to hot-iron and freeze banding. J. Anim. Sci. 76:972-979.

Smith, G. W., J. L. Davis, L. A. Tell, A. I. Webb, and J. E. Riviera. 2008. Extralabel use of nonsteroidal anti-inflammatory drugs in cattle. J. Am. Vet. Med. Assoc. 232:697-701.

Stafford, K. J. 2007. Alleviating the pain caused by the castration of cattle. Vet. J. 173:245-247.

Stafford, K. J., and D. J. Mellor. 2005a. The welfare significance of the castration of cattle: A review. N. Z. Vet. J. 53:271-278.

Stafford, K. J., and D. J. Mellor. 2005b. Dehorning and disbudding distress and its alleviation in calves. Vet. J. 169:337-349.

Stafford, K. J., D. J. Mellor, S. E. Todd, R. A. Bruce, and R. N. Ward. 2002. Effects of local anaesthesia or local anaesthesia plus a nonsteroidal anti-inflammatory drug on the acute cortisol response of calves to five different methods of castration. Res. Vet. Sci 73:61-70.

Stewart, M., K. J. Stafford, S. K. Dowling, A. L. Schaefer, and J. R. Webster. 2008. Eye temperature and heart rate variability of calves disbudded with or without local anesthetic. Physiol. Behav. 93:789-797.

Stewart, M., G. A. Verkerk, K. J. Stafford, A. L. Schaefer, and J. R. Webster. 2010. Noninvasive assessment of autonomic activity for evaluation of pain in calves, using surgical castration as a model. J. Dairy Sci. 93:3602-3609.

Stilwell, G., M. S. Lima, and D. M. Broom. 2008. Effects of nonsteroidal anti-inflammatory drugs on long-term pain in calves castrated by use of an external clamping technique following epidural anesthesia. Am. J. Vet. Res. 69:744-750.

Thornton, P. D., and A. E. Waterman-Pearson. 1999. Quantification of the pain and distress responses to castration in young lambs. Res. Vet. Sci. 66:107-118.

Thüer, S., S. Mellema, M. G. Doher, B. Wechsler, K. Nuss, and A. Steiner. 2007. Effect of local anesthesia on short- and long-term pain induced by two bloodless castration methods in calves. Vet. J. $173: 333-342$

Thun, R., E. Eggenberger, K. Zerobin, T. Luscher, and W. Vetter. 1981. Twenty-four-hour secretory pattern of cortisol in the bull: Evidence of episodic secretion and circadian rhythm. Endocrinology 109:2208-2212.

Ting, S. T. L., B. Earley, and M. A. Crowe. 2003a. Effect of repeated ketoprofen administration during surgical castration of bulls on cortisol, immunological function, feed intake, growth and behavior. J. Anim. Sci. 81:1253-1264.

Ting, S. T. L., B. Earley, and M. A. Crowe. 2003b. Effect of ketoprofen, lidocaine local anesthesia, and combined xylazine and lidocaine caudal epidural anesthesia during castration of beef cattle on stress responses, immunity, growth and behavior. J. Anim. Sci. 81:1281-1293.

USDA-APHIS (US Department of Agriculture Animal and Plant Health Inspection Service). 2008. Beef 2007-08, Part 1: Reference of beef cow-calf management practices in the United States, 20072008. \#N512-1008 37-40. USDA-APHIS-VS-CEAH, Fort Collins, $\mathrm{CO}$.

White, B. J., J. F. Coetzee, D. G. Renter, A. H. Babcock, D. U. Thomson, and D. Andresen. 2008. Evaluation of two-dimensional accelerometers to monitor beef cattle behavior post-castration. Am. J. Vet. Res. 69:1005-1012.

White, G. C., and R. E. Bennetts. 1996. Analysis of frequency count data using the negative binomial distribution. Ecology 77:2549 2557. 